\title{
CÂMERAS LEGISLATIVAS: VIDEOVIGILÂNCIA E LEIS NO RIO DE JANEIRO
}

\section{Bruno Cardoso}

\section{Introdução}

No presente artigo discuto a recorrência do recurso à videovigilância nas propostas legislativas que tratam de temas diversos, mas que têm em comum um discurso difuso sobre (in)segurança. Para tanto, são analisadas diferentes etapas dos processos de elaboração de leis versando sobre a instalação de câmeras em diferentes espaços, nos âmbitos federal, estadual e municipal, no intuito de compreender as principais linhas argumentativas de parlamentares (e também do prefeito da cidade) favoráveis e contrários ao uso desse expediente.

Creio que parte considerável do imaginário sobre o poder das câmeras se deve à ideia especificamente moderna (cartesiana) da separação entre corpo e mente, com a preeminência dessa última, apoiada na visão, sentido privilegiado no processo de apreensão racional do mundo.

Artigo recebido em 03/05/2011

Aprovado em 08/05/2012
$\mathrm{Na}$ parte final, comparo esses discursos e atos legislativos com minha experiência etnográfica em salas de monitoramento da Secretaria de Segurança do Rio de Janeiro, junto aos operadores de câmeras de vigilância. A partir dessa comparação, defendo a hipótese de que esse imaginário em torno do poder das câmeras muito se deve à percepção de pessoas e objetos técnicos como intrinsecamente separados, e, em especial, ao que chamo de sobredeterminação técnica, ideia que será explicada adiante.

\section{(In)segurança, videovigilância e legislação}

No Rio de Janeiro, a experiência cotidiana da insegurança é incontestável. Ainda mais significativo, o sentimento amplamente difundido de que esta vem aumentando progressivamente também aparece de forma generalizada e aparentemente incontestável. Entretanto, apesar da ligação intrínseca com a ideia de um crescimento da violência e 
da criminalidade urbana, não se pode inferir uma relação direta entre elas e a insegurança. A força dessa percepção não residiria em um aumento proporcional da violência, e muito menos poderia ser considerada um fenômeno contemporâneo. Já era possível observar discursos semelhantes desde o século XIX no Rio de Janeiro, sempre sendo apontado como contraponto um passado idealizado, no qual a violência era mais rara e os crimes menos graves (Bretas, 1997; Misse, 2006). No passado, as pessoas adotavam a mesma retórica atual - um "hoje violento" em oposição a um "ontem pacífico" -, num movimento que se repete indefinidamente. Projeta-se a imagem de um estado pacífico e idílico, para um tempo passado, que é mítico, já que nunca de fato teria existido.

A própria noção de insegurança não pode ser compreendida em separado da ideia de segurança, a promessa, ou a certeza, de que nada de extraordinário acontecerá. Mesmo se reduzido o sentido mais amplo da palavra segurança à ideia exclusiva de uma garantia de inviolabilidade do corpo e dos bens de uma pessoa, é provável que ela não passe de uma noção abstrata, impossível de ser concretizada na vida real. E é mesmo difícil imaginar que alguma configuração social, em qualquer época ou lugar, tenha efetivamente experimentado a ausência completa de riscos ou de imprevisibilidade, ou se sentido ao abrigo de inimigos, predadores, "forças da natureza" ou castigos divinos. A segurança, assim, só pode ser relativa, sempre havendo maior ou menor grau de insegurança na vida, coletiva ou individual.

A quimera de uma vida segura e isenta de perigos seria originária da promessa moderna de um mundo controlável, do qual a violência pudesse ser extirpada e a natureza, domesticada. Seria mesmo o caminho "natural" a ser percorrido na modernidade, culminando em uma sociedade segura baseada no aumento constante do conhecimento e no aperfeiçoamento da ciência e das tecnologias, sempre em direção ao progresso, capaz de eliminar um a um seus problemas e desvios, por meio do trabalho criterioso, competente (e moralmente neutro) de técnicos especialistas (Bauman, 1999). Desse contexto surgem as ideias gêmeas de segurança e insegurança públicas, que estariam indissociavelmente ligadas à emergência da noção do Estado como detentor do monopólio do uso legítimo da força, e à consequente mudança (lenta e processual) da própria relação estabelecida com a violência (Elias, 1993). A insegurança se deveria à própria existência do conceito de segurança, e mais especificamente de segurança pública, e a pressuposição de que cabe aos governantes garantir a proteção ao corpo e aos bens dos cidadãos.

Entretanto, ainda que supervalorizada por um processo de retroalimentação positiva, cumulativa e constante, sua existência é concreta: a partir dela as pessoas constroem representaçōes simbólicas, orientam o consumo e em sua função planejam e realizam as atividades práticas diárias. A insegurança age sobre as pessoas. E no combate a ela, toda a engenhosidade da razão é bem-vinda: legisladores, pesquisadores e industriais, ícones da racionalidade moderna, unem suas forças contra o inimigo comum. Helicópteros blindados, armas mais letais, armas não letais, radiotransmissores, aparelhos de escuta telefônica, bancos de dados etc. Os exemplos são infindáveis e necessitam de constante "atualização". Diante desse quadro, a instalação de sistemas de videovigilância policial em ruas das principais cidades brasileiras não apenas teve pouquíssima contestação pública, como foi regularmente saudada, pelo discurso oficial e também pela imprensa, como uma importante arma na luta diária do Estado para proteger a população. Essa tecnologia havia sido empregada em outros países ("de Primeiro Mundo!"), e dados de fontes nunca especificadas afirmavam tratar-se de incontestável sucesso. A adoção da videovigilância foi até certo ponto naturalizada como uma nova tecnologia que cedo ou tarde seria incorporada pela polícia, como outrora as impressōes digitais e os bancos de dados informáticos. Uma situação corriqueira e nada surpreendente, tanto no contexto das técnicas policiais como da informatização da vida contemporânea (De Blomac e Rousselin, 2008).

Além disso, a última década do século XX testemunhou a popularização da internet, assim como a avassaladora conquista de terreno da tecnologia digital. Em um curto período, a junção dessas duas inovaçôes técnicas transformou de forma radical a comunicação e, consequentemente, a vida social em todas as partes do mundo atingidas por tal re- 
volução. Passado o deslumbramento inicial e decorrido um tempo minimamente suficiente para a absorção dessas mudanças e das novas possibilidades abertas por elas, os mais diferentes setores da sociedade passaram a vislumbrar modos de utilizar essas tecnologias em proveito próprio.

Embalada pela retórica da violência e do medo, a indústria da segurança logo passa a investir na inovação tecnológica para criar e comercializar sistemas cada vez mais sofisticados e, em teoria, menos custosos, cujas promessas de proteção contra a violência e os riscos em geral têm o poder de rapidamente seduzir consumidores (privados ou públicos) amedrontados e dispostos a cada vez mais investir em sua própria segurança. ${ }^{1}$

É nesse contexto que surgem as primeiras apropriaçôes oficiais da videovigilância no Brasil. Revolução tecnológica, sentimento de insegurança e, em boa dose, forte crença no poder da visão e das imagens foram os principais ingredientes da intensa atividade legislativa em torno do assunto - que já podemos observar a uma década, e que será analisada a seguir. A vigilância eletrônica policial, campo empírico sobre o qual trabalhei (Cardoso, 2010), apesar de não regulamentada por legislação, surge dentro do mesmo movimento (a única lei federal sobre o assunto prevê apenas a obrigatoriedade da utilização de parte dos investimentos do Fundo Nacional de Segurança Pública em inovações tecnológicas, sendo a videovigilância explicitamente citada). ${ }^{2}$ A discussão em torno da videovigilância se deu de modo bastante diverso nos três âmbitos legislativos, estadual, municipal e federal. Uma análise mais detalhada das especificidades de cada um deles revela aspectos interessantes do imaginário sobre as câmeras de segurança, indispensável para a compreensão das dificuldades práticas de realização do trabalho de videomonitoramento.

\section{Assembleia Legislativa do Rio de Janeiro}

A esfera estadual foi o palco da maior parte das propostas legislativas com alguma implicação na cidade do Rio de Janeiro. A Assembleia Legislativa do Estado, ${ }^{3}$ do final de 1998 até meados de 2009, havia aprovado sete leis autorizando, regulamentando ou estabelecendo a instalação de câmeras de segurança em novos lugares, além de uma oitava proibindo a utilização de máquinas fotográficas em estabelecimentos de ensino da rede estadual. "Berçários", "unidades de terapia intensiva neonatal", "casas noturnas", "praças de pedágio", "estabelecimentos financeiros", "transporte metroviário", "bailes do tipo funk", "eventos de música eletrônica (festas rave)", "caixas eletrônicos", "instituiçõos carcerárias", cada um desses lugares foi, mediante legislação estadual, dotado de sistema de videovigilância, sempre com o intuito declarado de "aumentar a segurança" dos cidadãos. As duas primeiras leis instituem seu uso nos espaços bancários ${ }^{4}$ (agências ou terminais de autoatendimento), enquanto as outras buscavam responder diretamente a acontecimentos amplamente midiatizados, como "ataques de pitboys" (Cardoso, 2005) ou altas taxas de falecimento em algumas maternidades. Seja qual for o alvo dos deputados, o que mais interessa é o recurso recorrente ao artifício da captação e armazenamento de imagens como forma de combate a diversos problemas, da criminalidade à violência, do consumo de drogas à mortalidade neonatal.

As justificativas dos deputados autores das leis - obrigatoriamente presentes nos projetos de lei apresentados - são indicativos do discurso em torno da utilização de câmeras de vigilância, ou de segurança, ${ }^{5}$ e de sua ação esperada. Por exemplo, em 24 de março de 2004, durante um período marcado pelo grande destaque na imprensa carioca do que estava sendo chamado de "ataques de pitboys", o deputado coronel Jairo (PSC) apresenta em plenário o projeto de lei 1.389/2004, que em dois meses é transformado na lei 4.331, obrigando as "casas noturnas" a instalarem "circuito interno de TV" em seu interior. $\mathrm{Na}$ justificativa apresenta seus intuitos:

O funcionamento de casas noturnas deve ser permitido sem prejuízo, incômodo e lesōes físicas a seus frequentadores e vizinhança. Ocorre que brigas, confusões nessas casas noturnas têm sido estimuladas pela certeza da impunidade ocasionada pelo anonimato dos brigōes na falta de suas identificaçôes, ora por impossibilidade de reconhecimento face à confusão e tumulto ocasionados, ora pela intimidação psicológica e até física das vítimas e testemunhas. É por tais 
razões que venho procurar inibir essa insegurança ao público frequentador de boate e propor a obrigatoriedade de instalação de câmeras de vídeo com o fim de filmar seus frequentadores durante o horário de funcionamento, para uso exclusivo de ordem e segurança pública e a vir persuadir, prevenir e reprimir as possíveis brigas e confusões no interior do estabelecimento.

Visando "inibir a insegurança”, e para "uso exclusivo de ordem e segurança pública", o "circuito interno de TV" teria o poder de, aparentemente por si só, "persuadir, prevenir e reprimir" possíveis brigas e confusões, garantindo que nenhuma utilização indevida do sistema fosse realizada. $\mathrm{Na}$ explicação sobre o comportamento dos "brigões", oferecida pelo próprio deputado, é possível identificar a fonte de tanto poder conferido às câmeras: a "certeza da impunidade", ou objetivamente, o anonimato, falta de identificações e impossibilidade de reconhecimento, seja em função da confusão criada, seja por meio de intimidações físicas e psicológicas às testemunhas. $\mathrm{O}$ olhar eletrônico da videovigilância, além de ser capaz de captar e armazenar tudo, seria também um meio técnico objetivo, inintimidável, posto que não testemunha, mas elemento de prova, pièce à conviction (Derrida e Stiegler, 1996). $\mathrm{Se}$, no entanto, imaginarmos qualquer outra causa de briga que não a apontada pelo coronel Jairo (“certeza da impunidade"), é bastante provável que as capacidades de prevenção, persuasão e repressão fiquem um tanto prejudicadas.

Apenas seis dias depois dessa proposta de leilogo, em resposta à mesma onda de "ataques de pitboys" -, outro deputado, Domingos Brazão (PMDB), apresenta um novo projeto $(1.408 / 2004)$, posteriormente incorporado a essa mesma lei 4.331 (mas não aprovado), tornando obrigatória a instalação de "câmeras filmadoras na parte interior das casas de shows, boates, restaurantes, bares e similares afins", afirmando que "estas câmeras instaladas nos estabelecimentos que mencionam (sic), muito nos facilitará (sic) sua (sic) identificação desses agressores, permitindo inibi-los antes de qualquer ato de vandalismo". No caso, é o trabalho de prevenção operado pelas câmeras que é ressaltado como uma importante arma contra os vândalos, sem que de- mais explicações sejam transmitidas sobre como esse efeito seria obtido.

O projeto de lei 2.186, também de $2004,{ }^{6}$ mais tarde transformado na lei 4.917, de 8 de dezembro de 2006 (portanto, após mais de dois anos de tramitação), que tornava obrigatória a instalação de câmeras de vídeo em praças de pedágio, nos oferece uma justificativa diferente, dada por seu autor, o deputado Flávio Bolsonaro (PTB):

Temos assistido à divulgação, pela mídia, de inúmeros casos de contrabando de armas, drogas e outras mercadorias no âmbito de nosso Estado. Ocorre que, na grande maioria dos casos, esse transporte é feito pelas principais rodovias, sendo difícil a sua fiscalização, seja pela falta de efetivo e recursos de que dispóem nossas polícias, seja pelo grande fluxo de veículos, o que torna inviável a revista de todos eles.

Da mesma forma, é expressivo o número de sequestros onde as vítimas são transportadas em seus próprios veículos, seja em seu interior sob ameaça de armas ou nas malas, amarradas e amordaçadas.

Também é válido o argumento para justificar a presente iniciativa o fato de inúmeros crimes terem sido desvendados pelo Estado em virtude de filmagens efetuadas em estacionamentos e no interior de shopping centers, supermercados, lojas de conveniências e outros estabelecimentos comerciais ou de lazer.

Assim sendo, a presente iniciativa é de grande valia para que nossas polícias possam mapear as rotas de contrabando pelas rodovias e demais vias de nosso Estado, monitorando o movimento de veículos suspeitos e facilitando o combate ao crime organizado. Dispondo desse recurso nas praças de pedágio, fica impossível que um veículo e seu condutor, ao ingressar ou trafegar em território estadual, passe desapercebido pelas autoridades policiais.

Aqui os efeitos planejados pelo legislador parecem mais ambiciosos ainda do que na lei exami- 
nada anteriormente. Fica clara a ideia recorrente de que a instalação de câmeras passaria imediatamente a significar a realização de um trabalho vasto, tecnicamente complicado e extenuante, de monitoramento completo de todo o fluxo de veículos circulando pela malha rodoviária estadual do Rio de Janeiro. Contrabando, sequestro, tráfico, organização em quadrilha, todos esses crimes seriam mais bem prevenidos ou investigados com o simples artifício da câmera de vigilância nas praças de pedágio, ignorando todas as outras etapas do monitoramento em si, da manutenção diária dos computadores ao efetivo humano que lidaria com essas câmeras. O deputado imaginava uma capacidade de controle absoluta, suficiente para impossibilitar "que um veículo e seu condutor" passassem pela rede viária estadual "desapercebidos (sic) pelas autoridades policiais". Ao lermos as disposições da lei, é mencionado que as imagens ficariam arquivadas pelas concessionárias de rodovias durante um ano, e que só mediante autorização judicial, ou requerimento de autoridade policial competente, elas poderiam ser solicitadas, sem que nada, entretanto, fosse dito sobre monitoramento em tempo real, único modo de impedir que carros e motoristas percorram incógnitos as estradas. Além do mais, é difícil conceber como os veículos e as rotas seriam mapeados e monitorados apenas com circuitos de câmeras nas praças de pedágio, ainda que tenha aumentado sobremaneira o número de pedágios nas estradas. ${ }^{7}$

Um olhar ainda mais atento sobre a atividade legislativa no Rio de Janeiro - levando em conta os projetos de lei rejeitados ou ainda em tramitação - traz também à tona aspectos significativos do imaginário que envolve a videovigilância. Foram pelo menos 35 projetos de lei nos últimos dez anos, resultando nas sete leis anteriormente citadas. Versam sobre a instalação de câmeras em locais de divertimento (de casas noturnas a restaurantes), agências bancárias ou terminais de autoatendimento, ônibus, estádios, unidades hospitalares, escolas, shopping centers, museus, postos de gasolina, viaturas policiais, delegacias. Pode ser encontrada até mesmo uma proposta preconizando o monitoramento em tempo real das cozinhas de restaurantes por seus próprios clientes que, sentados no salão, acompanhariam em uma tela de TV a preparação dos alimentos, assim justificada por seu autor, o deputado Pedro Fernandes (PFL): ${ }^{8}$

O estado das cozinhas, o modo como os alimentos são acondicionados e preparados, as condições de higiene, são elementos com implicações diretas na saúde pública.

Tornar visível aos clientes o que ocorre nas cozinhas, sem dúvida, fará com que haja um maior cuidado dos estabelecimentos, hoje mais preocupados com a beleza do salão.

A vigilância nesse caso seria realizada pelos próprios fregueses do estabelecimento, cujos olhos seriam - literalmente - teletransportados da "região de fachada para a dos bastidores", como um modo de controlar todos os "segredos do espetáculo" (Goffman, 2002), ${ }^{9}$ certificando-se que nenhuma regra sanitária fosse descumprida no preparo de sua refeição. A possibilidade real de instalação de sistemas de câmeras em praticamente qualquer lugar é associada ao seu pretenso poder técnico de desempenhar múltiplas tarefas, quase sempre relativas ao controle ou à segurança. Assim, vemos dois projetos de lei praticamente iguais, mas com justificativas e efeitos imaginados diametralmente opostos. A instalação de câmeras em viaturas policiais, proposta pelo deputado Albano Reis (PMDB) em 2004, e quatro anos depois por Gilberto Palmares (PT), é um exemplo bastante característico disso. Vejamos as duas justificativas:

Considerando que a violência está quase que absolutamente fora de controle, e que a marginalidade, não poupa ninguém, e tem seu alvo principal voltado para o extermínio de policiais, tanto sejam, da PM, civis ou militares, para eles é indiferente, pois tem como objetivo só, o de matar, matar e matar, e depois roubar o que podem. E nós como ou enquanto parlamentares, temos por dever de ofício e também como cidadãos, tentar de todas as maneiras ser uma linha auxiliar neste combate.

Em assim, sendo, entendemos que municiar as viaturas das polícias militar e civil, com câme- 
ras de vídeo, que vem a ser um serviço monitorado por câmeras, que girarão em torno de 360 graus, colocadas no teto dessas viaturas, que terão um alcance máximo, para que, quando esta se aproximarem onde existam criminosos agindo, já poderiam estar preparadas. Lembremo-nos que em algumas ruas de nossa cidade, já existe este tipo de monitoramento, e que o crime foi diminuído. ${ }^{10}$

As polícias desempenham funções essenciais à manutenção da ordem pública, à preservação das liberdades individuais e dos direitos humanos. Caso aja mal, a polícia, por deter o monopólio estatal da violência legítima, é capaz de causar danos graves e irreparáveis, como o espancamento e a tortura de investigados, a falsa incriminação e o homicídio disfarçado de ato em legítima defesa. Exemplos de cometimento de abuso de poder por policiais não faltam. Ainda, a confiança da população nos policiais é extremamente tênue. Por esses motivos, as polícias devem, mais do que outras instituições públicas, ser submetidas a rígido controle.

A previsão constitucional da fiscalização da polícia não foi feita à toa. $\mathrm{O}$ risco de os policiais se utilizarem de suas armas e de seu poder para perpetrarem abusos, obterem vantagens pessoais e intimidarem inimigos é o fundamento da norma. A autonomia dos órgãos públicos é desejável, mas não pode se travestir em argumento para que agentes e instituições se escusem do controle. ${ }^{11}$

Os meios técnicos e a tecnologia são, em teoria, moralmente neutros. Entretanto, fato de extrema importância para a questão da videovigilância, a técnica se constitui como real apenas através da ação humana, e esta desconhece a neutralidade moral. No caso, a instalação de câmeras pode responder aos anseios dos dois grupos que há décadas se colocam em posiçóes antagônicas na discussão sobre segurança pública no Rio de Janeiro, os que pregam constantemente mais poder para as forças policiais e os que pedem cada vez maior controle de sua atuação.
Experiências semelhantes às que pregam esses projetos de lei, em outros lugares, indicam que mesmo que inicialmente as imagens obtidas tivessem o intuito de combater determinados comportamentos policiais, isoladamente são incapazes de fazê-lo. Nos Estados Unidos, por exemplo, como indica Christopher Stone (2003), as alegações de conduta indevida por parte de agentes fizeram com que câmeras fossem instaladas em algumas viaturas e delegacias de determinados estados, contudo o exame das gravações, por superiores, não teria sido incorporado à rotina de trabalho policial, impossibilitando a iniciativa de surtir o efeito esperado por seus elaboradores. ${ }^{12} \mathrm{Na}$ Inglaterra, visando reduzir o número de mortes de pessoas sob custódia da polícia, foram colocadas câmeras nos lugares em que suspeitos e presos ficavam custodiados e em algumas celas policiais (Graham, 2003). O caso inglês, no entanto, é especial, por ser o país onde a videovigilância se tornou mais corriqueira e praticamente onipresente. No estado do Rio de Janeiro também foi apresentado um projeto de lei (920/1999, do deputado Paulo Melo) preconizando a instalação de circuito interno de filmagem no interior das delegacias, com a justificativa de "garantir a integridade física de presos, policiais, advogados, visitantes e circunvizinhança das unidades carcerárias".

Um ponto que nunca é ressaltado pelo discurso dos legisladores é que tamanha quantidade de câmeras requer um número considerável de pessoas as observando, seja incluindo-as, adaptando-as em uma rotina de trabalho já existente, seja criando novos postos especializados. Se levada às últimas consequências essa incorporação dificilmente seria possível, dada a quantidade de informação disponível que deveria ser analisada diariamente. E mesmo que o contingente de pessoas bastasse, a centralização de todas as informações é tarefa de execução complexa, e a criação de um grande banco de dados imagético é uma promessa, ou ameaça, desejada desde o século XIX (Sekula, 1986), porém ainda longe de ser concretizada.

\section{Câmara dos Vereadores do Rio de Janeiro}

No âmbito municipal, a atividade legislativa em torno das câmeras de vigilância, apesar de não 
desprezível, é bastante inferior à encontrada entre os deputados estaduais fluminenses (que apresentaram 35 projetos, aprovando sete leis). A Câmara Municipal do Rio de Janeiro, ${ }^{13}$ entre os anos de 2001 e 2009, votou "apenas" seis projetos de lei preconizando a instalação de sistemas de videovigilância, sendo que somente a metade foi aprovada, tendo se tornado lei. O mais curioso, entretanto, é o fato de que duas dessas leis foram vetadas pelo então prefeito César Maia - PFL, que se tornou assim uma voz dissonante quanto ao crescente uso de tal dispositivo. Contudo nos dois casos os vetos foram quebrados pelos vereadores e as leis promulgadas, mesmo diante da rejeição do Executivo.

Se em relação à primeira das leis vetadas ${ }^{14} \mathrm{a}$ argumentação apontava para sua inconstitucionalidade, por implicar aumento de gastos e interferência na esfera decisória do poder Executivo, a justificativa da segunda ${ }^{15}$ já é bastante diferente, e de elevado interesse para a presente discussão. Vejamos então como o prefeito justificou seu veto:

A obrigatoriedade na utilização de detectores de metais e de circuito interno de câmeras de filmagens em boates, casas noturnas e similares tem por finalidade aperfeiçoar os mecanismos de controle e identificação de pessoas que têm deixado rastro de violência nas noites do Rio de Janeiro, buscando-se, assim, salvaguardar a incolumidade física e a segurança dos cariocas. [...]

Resta clara, portanto, a existência de conflito de dois direitos fundamentais, igualmente tutelados pela Carta Magna: o direito à segurança e o direito à intimidade e à vida privada. [...]

Assim sendo, o uso obrigatório de detectores de metais e de circuito interno de câmeras de filmagens, como meios restritivos do direito à intimidade e à vida privada, não se justificam no momento em que há outras maneiras, igualmente eficientes e menos gravosas à intimidade, para a preservação da segurança dos cidadãos, tais como o reforço na equipe de se- gurança, ou o cadastro do documento de identidade dos frequentadores de casas noturnas. Nesse sentido, torna-se cristalino que a implementação da medida proposta no projeto em tela não observa o princípio da proporcionalidade, porquanto há como preservar a segurança dos cidadãos sem que seja necessário limitar tão intensamente o seu direito à intimidade e à vida privada. Há, então, meios eficientes e menos onerosos para tutelar o mesmo fim, que, como corolário do princípio da proporcionalidade, afastam a proposição em análise.

Apesar de reconhecer o valor da videovigilância no combate à violência em casas noturnas, assunto que tinha considerável destaque na imprensa carioca naquele momento, César Maia afirma achá-la problemática por conflitar dois direitos fundamentais. Um exagero totalitário, uma resposta desmedida ao perigo dos pitboys, enfim, uma rajada de controle em um momento e local em que o descontrole, mesmo que não absoluto, é socialmente tolerado, ou mesmo esperado. Ao se filmar tudo o que todos fazem em todas as casas noturnas e boates $\mathrm{da}$ cidade, muitos atos que deveriam ser efêmeros e quase invisíveis ganham a possibilidade de não somente serem vistos, mas também "eternizados", seja em grandes bancos de dados de segurança seja na internet, o grande banco de dados coletivo e mundial. A lógica securitária, embora não contradita, é pesada, relativizada, sendo considerada pelo alcaide como "ferindo o princípio da proporcionalidade" e limitando "intensamente o direito dos cidadãos à intimidade e à vida privada", sem que tal medida seja absolutamente necessária na preservação da segurança destes. Um argumento em consonância com a principal crítica em relação à videovigilância, qual seja, sua caracterização como violadora em potencial da intimidade e privacidade daqueles captados pelas lentes de suas câmeras. Trata-se de uma ideia cuja popularidade, se em muito deve à capacidade literária de George Orwell (em 1984) e ao imaginário criado em torno de seu Big Brother, já era embrionária há muito tempo no pensamento ocidental, embora com as devidas adaptaçôes tecnológicas, como lembra Foucault (2003), ao falar de Bentham e de seu Panóptico. 


\section{Câmara dos Deputados}

No âmbito federal, ${ }^{16}$ por sua vez, somente um projeto de lei, de 2007, relativo à instalação de câmeras de segurança foi aprovado, e não como uma nova lei, mas como alteração de uma preexistente, versando sobre a aplicação dos recursos do Fundo Nacional de Segurança Pública. É acrescentado que, entre outras aplicações em tecnologia, o investimento em "sistemas de vigilância monitorada por câmeras em locais de alto fluxo de pessoas" e "sistemas de vigilância eletrônica em áreas residenciais" deveria ser prioritário. É pouco, ainda mais se tivermos em conta que onze projetos de lei foram apresentados desde 2003, todos tendo sido rejeitados ou ainda tramitarem em alguma comissão. A leitura dos pareceres negativos apresenta indícios que ajudam a esclarecer a razão dessa taxa de aprovação de projetos relativos à videovigilância muito inferior à encontrada nos legislativos municipal e federal. Nem mesmo de forma paralela, por exemplo, argumentos como os encontrados na justificação de veto do prefeito do Rio de Janeiro aparecem nos votos e nas recomendações de votos dos relatores. Os direitos à privacidade e à intimidade não são em momento algum lembrados ou mencionados. ${ }^{17}$ Os custos, tanto de instalação como de operação diária e de manutenção, dominam as justificativas de votos negativos, sendo possível igualmente perceber que a vastidão do âmbito legislativo federal por vezes faz com que a aplicação prática da lei pareça exagerada, e que o projeto tenha menores possibilidades de "vingar". É o que podemos ver no parecer dado pelo deputado Airton Roveda (PR-PR), rejeitando o projeto que previa a obrigatoriedade da instalação de sistema de câmeras e GPS em ônibus e micro-ônibus do país inteiro: ${ }^{18}$

[...] o ente federativo que conhece com mais propriedade as características de seu sistema de transporte poderá instituir quaisquer medidas de segurança que julgar adequadas à sua realidade, sem necessidade de uma regulação federal única. Por que motivos haveríamos de impor a qualquer município, por menor que seja e mesmo que não tenha maiores problemas de segurança pública, a utilização de veículos mais caros, por serem dotados de circuitos internos de TV?
Da mesma forma, ao justificar sua rejeição ao Projeto de Lei 3.279, ${ }^{19}$ de 2008 , que previa a obrigatoriedade da instalação de câmeras de vigilância em todos os condomínios do país - residenciais ou comerciais - o deputado Paulo Maluf (PP-SP) atenta para a amplidão da proposta, assim como para a variedade de locais implicados por ela:

Há, por exemplo, condomínios em cidades do interior, onde a criminalidade é bastante baixa e a instalação desse tipo de sistema é completamente desnecessária. Por sua vez, há condomínios de casas em regiôes litorâneas onde a instalação desse tipo de sistema pode adquirir um custo desproporcional, em razão da extensão do terreno. Há, por outro lado, condomínios em regiōes pobres, que simplesmente não teriam condiçôes de cumprir a lei. Há casos onde pode ser mais benéfico a instalação de grades ou cercas do que a instalação desse tipo de sistema ou situações onde o condomínio acredite ser mais benéfico investir em mais treinamento para seus funcionários.

No entanto, mais interessante é o questionamento encontrado no discurso de alguns relatores à pretensa eficácia indiscutível da videovigilância. Essa postura vai de encontro à justificativa observada no veto do então prefeito do Rio de Janeiro, assim como à crença no poder das câmeras, responsável pela avalanche de projetos e leis surgidas na Assembleia Legislativa do Rio de Janeiro. As câmeras não constituiriam ameaça de controle sobre a vida privada simplesmente por não serem consideradas capazes de controlar e impedir nem os comportamentos criminosos. Vejamos o que dizem os próprios deputados:

[...] caso seja implantado o sistema, a relação custo x benefício será pífia, no que concerne aos benefícios. A instalação de câmeras apenas indicarão (sic) o número de assaltantes, se eles estiverem usando dispositivos que impeçam a visualização de seus rostos. E, ainda que a identificação visual seja possível, câmeras não impedem assaltos e os moradores terão que depender da disponibilidade de recursos - huma- 
nos e materiais - da polícia para a realização de investigaçôes que levem à prisão dos criminosos. Isso, se a qualidade da imagem ou o ângulo de filmagem permitir a identificação. Em caso contrário, a polícia acabará localizando os criminosos usando os métodos tradicionais de investigação que já dispõe. ${ }^{20}$

É necessário que seja melhor avaliada a eficácia da medida proposta, uma vez que não foram apresentados dados conclusivos sobre o fato de que a colocação de câmeras inibe, por si só, a ação de meliantes. Se assim o fosse, não existiriam mais assaltos a bancos, estabelecimentos comerciais e condomínios que possuem sistema de vigilância monitorada por câmeras de vídeo. ${ }^{21}$

Mesmo se levados em conta todos os fatores e interesses externos à atividade parlamentar, de influência decisiva nos lobbies ${ }^{22}$ que circundam os deputados e nos processos decisórios dos quais estes participam, os argumentos apresentados não devem ser ignorados. A videovigilância não é incontestável, e a persistência de crimes e atos violentos em áreas dotadas de tais sistemas é um dado que não pode ser ignorado. Fato também lembrado pelos parlamentares, o alto custo de manutenção e instalação de circuitos de câmeras de vigilância desnecessários, e possivelmente inúteis, fariam deles muitas vezes um transtorno maior para as pessoas que deveriam proteger do que para quaisquer outras que por ali circulam. Até por estarem previstas sançōes restritivas de liberdade para aqueles que não cumprirem a regulamentação estabelecida nas leis que se tentava aprovar. Propõe-se a criação de um contexto de criminalização da não videovigilância. $\mathrm{Na}$ maioria das vezes, uma lei que obriga tem maior ingerência sobre a vida das pessoas do que uma que "apenas" proíbe. Sua fiscalização, no entanto, é mais extensa e difícil, acarretando frequentemente maior frouxidão e tolerância por parte dos fiscais responsáveis. De qualquer modo, a obrigatoriedade da videovigilância em todos os prédios e condomínios do Brasil foi rejeitada por todos os relatores e comissóes pelas quais o projeto passou, numa indicação de que, ao menos por enquanto, parece longe de ser vista como uma alternativa aplicável no combate à insegurança.

\section{Visão e apreensão do mundo}

Um movimento característico da emergência da racionalidade moderna é a valorização da capacidade cognitiva dos sentidos (percepção), que passam a ser tomados como forma por excelência de apreensão do mundo. Além disso, há uma forte tradição de pensamento e argumentação em torno da ideia da visão como sentido privilegiado no processo de apreensão do mundo, como mediador entre a subjetividade e o mundo objetivo, externo. ${ }^{23}$ As câmeras expandiriam as possibilidades dessa interação, transportando a visão para longe do corpo e da presença daquele que olha, aumentando o poderio e o alcance da razão, parecendo capazes de não apenas controlar como também de ameaçar a intimidade e a privacidade de pessoas cujas imagens são capturadas. Nesse sentido, é incontornável a teoria foucaultiana sobre o diagrama de poder disciplinar (Foucault, 2003), em especial a dissociação do par ver-ser visto, que implicaria obrigatoriamente o estabelecimento de uma assimetria de poder aumentada entre observadores e observados, resultando em ainda mais controle disciplinar. $\mathrm{O}$ acesso às imagens dos indivíduos, que além de visualizadas em tempo real também são gravadas e arquivadas, contribuiria para que cada vez mais informações sobre cada um estivessem disponíveis ao poder disciplinar, permanentemente fortalecido através desse processo. ${ }^{24}$ Essa é, em maior ou menor grau, uma reflexão presente em toda a discussão legislativa em torno da videovigilância. E, de forma previsível, apareceu também como central ao longo do trabalho etnográfico que realizei com operadores de câmeras de vigilância policial. Durante os meses de pesquisa de campo - tanto na central de câmeras da polícia militar do Estado do Rio de Janeiro quanto na "sala de operações" do batalhão de Copacabana,$-{ }^{25}$ pude entender o quanto a visão era insuficiente para a compreensão das cenas expostas nas telas. Imagens em excesso, por todos os lados, se multiplicando a cada dia, ao contrário do que se promete - e teme - estão longe de proporcionar uma capacidade multiplicada de ver e saber, de captar e interpretar a realidade. Identifico, nesse sentido, duas razões especiais. 
A primeira é que imagens mudas, distantes, quase sem cor e de difícil contextualização - por maior que possa ser a importância da visão na apreensão do mundo - dizem menos sobre o que está acontecendo no local filmado do que os promotores das câmeras gostariam de admitir. Se as "estátuas pensantes" das quais fala Elias (1994) não podem se movimentar, tocar, sentir, interagir, se imiscuir com o mundo, mas apenas observá-lo, refletir e interpretá-lo, talvez não sejam capazes com isso de um conhecimento mais racional sobre a realidade, mas apenas de um conhecimento mais incompleto. A própria divisão da percepção humana em cinco sentidos estanques, proposta por Aristóteles e amplamente aceita na tradição de pensamento ocidental, não deveria ser tomada como uma reprodução, ou uma tradução literal, do esquema sensorial humano, mas como um sistema classificatório, que ilustra, mas também organiza e contribui na construção de conhecimentos práticos e interpretações teóricas a propósito das vidas psíquica e social, o que tornaria ainda mais inconsistente a ideia da preeminência de um desses sentidos sobre os outros. Inconsistência que se torna ainda maior, se concordarmos com o que Csordas (2008) chama de "paradigma da corporeidade", segundo o qual o corpo é tomado não mais como objeto da própria percepção, mas como sujeito do processo de percepção, rompendo assim com a dicotomia cartesiana entre corpo e mente, essencial para a representação do "indivíduo ocidental moderno" descrito por Elias. A percepção, dessa forma, não poderia ser dividida e localizada em determinados órgãos ou regiōes do corpo humano, mas agiria através deste como um todo: a visão não dependeria apenas de olhos, ligações nervosas e áreas determinadas do cérebro, mas estabeleceria uma série de outras conexões, físicas ou não, entre diferentes partes do corpo.

Entretanto, mesmo se tomarmos como base o esquema aristotélico, podemos afirmar que o projeto de lei (estadual) que versa sobre a instalação de câmeras nas cozinhas dos restaurantes, com imagens transmitidas diretamente para o salão onde os fregueses fazem a refeição, reveste a visão de demasiado poder e ignora as consequências da fragmentação sensorial (a câmera proporciona uma transposição parcial da visão, mas não, do olfato e da audição) na construção de sentido necessária à fiscalização pretendida. O mesmo pode-se perceber em relação às preocupaçóes do então prefeito do Rio de Janeiro a propósito de uma suposta invasão da privacidade dos frequentadores das casas noturnas, já que a observação distanciada de imagens mudas dificilmente teria essa capacidade. Até porque a intimidade envolve muito mais coisas do que aquilo que pode ser captado e transmitido por sistemas de videomonitoramento.

A visão dá acesso, decerto, a alguns aspectos da "realidade", porém estes dificilmente bastam para uma contextualização mínima dos acontecimentos observados, prejudicando consideravelmente a compreensão das imagens. Por exemplo, delitos como o consumo de maconha, cujo indício mais perceptível é o odor que provoca, ou o disparo de uma arma de fogo, mais facilmente discernível pelo som consequente, têm sua identificação dificultada a partir apenas das câmeras de vigilância. A descontextualização das cenas impede quase todo o tempo a construção de narrativas minimamente estruturadas, capazes de despertar o interesse e manter a atenção dos observadores. Parte importante das exceções são cenas que muito pouco ou nada têm a ver com as questôes de segurança pública que justificam a instalação da videovigilância. Assim, acompanhei a alegre e comentada observação de mulheres sambando no calçadão, uma animada reunião de pessoas em um bar no início da manhã, um rapaz apelidado de "gordinho" fazendo, com dificuldades - diante da gozação dos operadores -, abdominais na areia e, constantemente, a contemplação de corpos femininos na praia. Ao contrário da observação vigilante, dominada pelo que Smith (2004) chamou de "fator tédio" - rotina de trabalho composta por horas de visualização de cenas cotidianas em que predomina o sentimento de que "nada acontece" -, o olhar voyeurístico desperta o interesse dos operadores de câmeras, os quais a partir dele constroem narrativas que os permitem manter a atenção voltada para o que está sendo observado. ${ }^{26}$

\section{Agenciamentos sociotécnico}

Isso nos leva diretamente à segunda razão pela qual os sistemas de videovigilância se mos- 
tram menos capazes do que pensam os deputados fluminenses de desempenhar as inúmeras funções que lhes são imputadas: os elementos humanos e tecnológicos que os compõem são sempre tomados de maneira isolada. Estes elementos constituem, em efeito, agenciamentos sociotécnicos (Callon, 2003), ou seja, redes materialmente heterogêneas formadas por humanos e não-humanos, e que só têm existência através da interação criadora dos diversos elementos que as compõem (Law, 1992). No caso específico aqui tratado, o agenciamento é composto - de maneira bastante simplificada - por câmeras instaladas em pontos de observação, redes de transmissão de dados (modem, antena, ondas de rádio, cabo de fibra ótica, linha telefônica etc.), computadores onde as imagens são visualizadas, softwares de visualização das imagens, vigilantes (operadores de câmeras), rádio de transmissão e policiais nas ruas em contato com os operadores. Sem a interação cooperativa entre esses homens, máquinas e tecnologias não há videovigilância. As imagens dependem de olhos humanos para adquirirem existência efetiva (as máquinas não veem, apenas captam e (re)transmitem), e os vigilantes dependem dos dispositivos tecnológicos para enxergarem além do que se encontra dentro de seu campo de visão imediato, assim como para armazenar e reproduzir as cenas observadas.

A organização dos atores (humanos e não humanos) em rede não é levada em conta pelas promessas, projetos e temores que acompanhavam a videovigilância. Na maior parte do tempo é conferida excessiva importância aos meios técnicos, sendo negligenciado o aspecto humano do sistema. Essa sobredeterminação técnica cria a expectativa de que a mera instalação de câmeras seja capaz de realizar o trabalho de vigilância/monitoramento. A realidade prática mostrou-me o quanto é errônea essa concepção, já que o funcionamento do sistema depende essencialmente do trabalho dos operadores, assim como das interações entre estes e as tecnologias que devem manejar. Como consequência, o treinamento e a capacitação dos operadores não aparecem no planejamento nem na legislação - em parte porque, de modo extremamente simplificador, o principal pré-requisito desse trabalho é a capacidade de olhar. Policiais e bombeiros aposenta- dos foram escolhidos para desempenhar o serviço, a maior parte deles com idade próxima ou superior a 70 anos, com todas as dificuldades de enxergar próprias dessa faixa etária. Mais importante ainda, eram pessoas com considerável inabilidade em lidar com os artefatos tecnológicos que constituíam o seu trabalho. Antes da contratação, poucos tinham tido contato com microcomputadores e nenhum deles falava inglês, idioma do software utilizado para a operação das câmeras, assim como para a visualização das imagens, provavelmente em função da faixa etária e do nível socioeconômico desses policiais e bombeiros aposentados. ${ }^{27}$

Ignorando tais fatos, a legislação e as políticas públicas partem do pressuposto de que basta o aparato tecnológico ser instalado para que suas promessas de eficácia sejam cumpridas. Com o sistema sendo pensado a partir da lógica da sobredeterminação técnica, o papel desempenhado pelos humanos envolvidos na videovigilância é visto como se fosse marginal ao seu funcionamento. Um exemplo paradigmático disso é a já mencionada lei 4.917/06, do deputado Flávio Bolsonaro, que obrigava a instalação de câmeras em todas as praças de pedágio do Estado, para que nenhum veículo e seu condutor passassem incógnitos pelas rodovias do Rio de Janeiro. Vale lembrar que no único posto de pedágio da RJ-124 (Via Lagos), por exemplo, no ano de 2009 passaram 5,22 milhões de veículos, ${ }^{28}$ enquanto na ponte Rio-Niterói foi registrada a passagem de mais de 52 milhões de veículos. ${ }^{29}$ Além disso, realizar buscas no arquivo anual ou monitorar o fluxo diário de carros, caminhões, ônibus e motocicletas, é um trabalho que requer grande quantidade de funcionários e olhos humanos, mesmo com o mais moderno aparato tecnológico.

\section{Conclusão}

Uma questão fundamental para compreender o crescente uso da tecnologia de captação de imagens, de forma pública ou privada, regulamentada ou não por lei, pode ser resumida de forma simplificada através da pergunta "por que não?". Diante da possibilidade aberta pela tecnologia e da adoção indiscriminada da videovigilância pela iniciativa privada, 
não parece fazer sentido impedir o poder público de agir dessa maneira, ainda mais se o faz em nome do "combate à insegurança". Videovigiar já faz parte do repertório básico desse combate, mesmo que não tenha a ver com resultados efetivos ou com uma real contribuição para a segurança pública. Até porque a imagem é um poderoso elemento ilustrativo, e poucos exemplos já são suficientes para causar impacto e construir uma reputação de eficiência.

Entretanto, boa parte das discussões e iniciativas legislativas tomadas nesse sentido tem em comum tanto a valorização excessiva de uma visão descontextualizada e fragmentada, como o que chamei de sobredeterminação técnica, a ideia de que para o trabalho de videovigilância bastaria a instalação de câmeras no ponto a ser monitorado. Assim, o que acontece com frequência é que praticamente a totalidade das imagens se perde, existindo materialmente em arquivo digital por alguns dias (trinta, no caso que estudei, da Secretaria de Segurança do Rio de Janeiro), e desaparecendo sem deixar nenhum traço dessa existência, sem ter mesmo, majoritariamente, sido vista uma única vez. Um imenso contingente de cenas são criadas e destruídas cotidianamente, sem terem nunca sido atualizadas através do olhar humano, ou seja, nunca tendo existido realmente, apenas como virtualidade. São imagens latentes que, se não vistas durante o breve período durante o qual podem ser atualizadas, e assim transformadas em imagens reais, são destruídas, transformadas em não imagem, em uma possibilidade não concretizada de imagem. A superabundância imagética gerada faz com que a videovigilância produza uma quantidade sempre muito superior de não imagens do que de imagens. Afinal, se é verdade incontestável que mais e mais imagens digitais são produzidas a cada dia, também o é que mais e mais imagens digitais não são vistas a cada dia. E muito a ser visto não indica, de modo algum, uma melhor ou mais eficiente vigilância. Pelo contrário, quanto maior o campo de visão, mais difícil é a observação atenta de cada um dos seus pontos.

\section{Notas}

1 Ver, por exemplo, Heilmann (2005).

2 No Rio de Janeiro, a Secretaria Nacional de Segurança
Pública investiu soma considerável na aquisição e instalação de câmeras e salas de controle, em especial no período dos Jogos Pan-Americanos (2007), e promete multiplicar o investimento em função dos megaeventos esportivos que a cidade irá sediar (Jogos Olímpicos de 2016 e final da Copa do Mundo de 2014).

3 As informações referentes ao Poder Legislativo fluminense foram retiradas do site da Alerj: www.alerj. rj.gov.br.

4 Leis 3.162, de dezembro de 1998, e 3.663, de outubro de 2001 .

5 A escolha entre os termos segurança ou vigilância diz bastante sobre a perspectiva adotada por quem fala, sendo o primeiro normalmente elogioso e o segundo crítico. Na polícia militar do Rio de Janeiro usava-se habitualmente um terceiro termo, monitoramento.

6 Em toda a última década (quando ganhou força a própria ideia de videovigilância na legislação brasileira), o maior número de projetos de lei (nove) relativos a câmeras de segurança foi apresentado no ano de 2004. Em 1999 foram sete, em 2000, 2001, 2005 e 2009 apenas um, em 2003 e 2007 três e em 2006 dois. No ano de 2008 foram seis, enquanto, surpreendentemente, nenhum projeto foi encontrado em 2002.

7 Em janeiro de 2010 eram 24, nas seguintes estradas: BR-040 (2), BR-101 (5), Ponte Rio - Niterói (1), BR-116 (7), BR-393 (3), RJ-116 (4), RJ-124 (1) e Linha Amarela (1). Fonte: <http://www.emsampa.com. br/pedrj.htm>

8 Projeto de Lei 1.213/2007.

9 Curiosamente o exemplo da cozinha do restaurante (de um hotel, no caso) é citado por Erving Goffman para explicar os conceitos aqui discutidos.

10 Projeto de Lei 1.896/2004, de autoria de Albano Reis.

11 Projeto de Lei 1.625/2008, de autoria de Gilberto Palmares.

12 Pelo que pude perceber no campo, houve, até certo ponto, um acréscimo de controle sobre os policiais nas ruas, em especial os fardados (PM). Goold (2003) indica ter acontecido fenômeno semelhante na Grã-Bretanha.

13 As informações relativas à Câmara dos Vereadores do Rio de Janeiro foram retiradas de seu site oficial $<$ www.camara.rj.gov.br>.

14 Lei 4.133, de 2005, inicialmente Projeto de Lei 1.394 de 2003, que "autoriza o Poder Executivo a implantar, nas unidades da rede municipal de ensino, Sistemas de Monitoramento por Câmeras de Vídeo, e dá outras providências", de autoria do vereador Jorge Mauro (PT do B). 
15 Lei 3.790, de 2004, inicialmente Projeto de Lei 1.943, também de 2004, que "Institui o uso obrigatório de detectores de metais e circuito interno de câmeras de filmagem, nos estabelecimentos que menciona, e dá outras providências", de autoria do vereador Rodrigo Bethlem (PMDB).

16 As informações relativas à Câmara dos Deputados foram retiradas de seu site oficial $<$ http://www2.camara. gov.br/>.

17 Uma hipótese seria a de que tais questôes teriam maior importância para os moradores de grandes cidades, pela própria origem e disseminação maior de tais categorias (privacidade e intimidade) na vida do cidadão urbano.

18 Projeto de Lei 6.649, de 2006, de autoria de Mário Negromonte (PP-BA).

19 De autoria de Vic Pires Franco (DEM-PA).

20 Parecer do deputado Alexandre Silveira (PPS-MG), ao Projeto de Lei 3.604, de 2008, autoria do deputado Vic Pires Franco.

21 Parecer do deputado Airton Roveda (PR-PR), ao Projeto de Lei 6.649, de 2006, de autoria do deputado Mário Negromonte (PP-BA).

22 Por exemplo, da indústria de segurança, mas também outros, como de empresas de transportes coletivos, não dispostas a realizar tais investimentos tecnológicos.

23 Um bom exemplo é a metáfora das estátuas pensantes, da qual faz uso Elias (1994).

24 É grande a influência dessa perspectiva sobre os estudos de vigilância (Lyon, 2001; Whitaker, 1999), assim como são interessantes as críticas ao seu uso no contexto contemporâneo (Koskela, 2004; Lianos, 2003).

25 O 19o BPM, localizado em Copacabana, também tem em sua área de abrangência o bairro do Leme.

26 Não pretendo com isso afirmar que o sistema de videovigilância policial que pesquisei seja constante instrumento de observação voyeurística, embora esse tipo de olhar seja o principal alvo da fiscalização dos superiores no interior do próprio sistema, o que apenas demonstra o quanto seu risco é concreto.

27 Eram praças, de posto entre cabo e subtenente, e majoritariamente tinham se voluntariado para desempenhar o serviço em função de dificuldades financeiras.

28 Disponível em <http://www.rodoviadoslagos.com.br/ sobre/NumerosCocessionaria.aspx $>$.

29 Disponível em <http://www.ponte.com.br/sobre/NumerosCocessionaria.aspx>.

\section{BIBLIOGRAFIA}

BAUMAN, Zygmunt. (1999), Modernidade e ambivalência. Trad. Marcus Penchel. Rio de Janeiro, Jorge Zahar.

BRETAS, Marcos Luiz. (1997), Ordem na cidade: o exercício cotidiano da autoridade policial no Rio de Janeiro, 1907/1930. Rio de Janeiro, Rocco.

CALLON, Michel. (2003), "Quel espace publique pour la démocratie technique?”, in D. Cefaï e D. Pasquier (orgs.), Les sens du public: publics politiques, publics médiatiques, Paris: CURAPP/PUF.

CARDOSO, Bruno. (2005), Briga e castigo: sobre pitboys e "canais de fofoca" em um sistema acusatório. Dissertação de mestrado, Rio de Janeiro, Programa de Pós-Graduação em Sociologia e Antropologia (UFRJ). . (2010), Todos os olhos: videovigilâncias, videovoyeurismos e (re)produção imagética na tecnologia digital. Tese de doutorado, Rio de Janeiro, Programa de Pós-Graduação em Sociologia e Antropologia (UFRJ).

CSORDAS, Thomas. (2008), Corpo/significadol cura. Porto Alegre, Editora da UFRGS.

DE BLOMAC, Françoise \& ROUSSELIN, Thierry. (2008), Sous surveillance! Démêler le mythe de la réalité. Paris, Les Carnets de l'Info.

DERRIDA, Jacques \& STIEGLER, Bernard. (1996), Échographies de la télévision: entretiens filmés. Paris, Galilée/INA.

ELIAS, Norbert. (1993), O processo civilizador. Trad. Ruy Jungmann. Rio de Janeiro, Jorge Zahar, vols. 1 e 2.

. (1994), A sociedade dos individuos. Trad. Vera Ribeiro. Rio de Janeiro, Jorge Zahar. FOUCAULT, Michel. (2003), Vigiar e punir: nascimento da prisão. 27. ed. Trad. Raquel Ramalhete. Petrópolis, Vozes.

GOFFMAN, Erving. (2002), A representação do eu na vida cotidiana. 10. ed. Trad. Maria Célia Santos Raposo. Petrópolis, Vozes.

GOOLD, Benjamin J. (2003), "Public area surveillance and police work: the impact of CCTV on police behavior and autonomy". Surveillance \& Society, 1 (2). Disponível em $<$ http://www.surveillance-and-society.org/articles1(2)/publicpolice.pdf>. 
GRAHAM, Sir Alistair. (2003). "Uma visão sobre a Police Complaints Authority", in Julita Lemgruber; Leonarda Musumeci e Ignácio Cano (orgs), Quem vigia os vigias? Um estudo sobre controle externo da polícia no Brasil, Rio de Janeiro/São Paulo, Record.

HEILMANN, Éric. (2005), "Le marché de la vidéosurveillance: du maintien de l'ordre public à la gestion des (dés)ordres privés". Informations Sociales, 126.

KOSKELA, Hille. (2004), "Webcams, TV shows and mobile phones: empowering exhibitionism”. Surveillance \& Society, 2 (2/3). Disponível em <http://www.surveillance-and-society. org/articles2(2)/webcams.pdf>.

LAW, John. (1992), "Notes on the theory of actor network: ordering, strategy and heterogeneity”. Lancaster, Centre for Science Studies, Lancaster University. Disponível em <http:// www.lancs.ac.uk/fass/sociology/papers/law-notes-on-ant.pdf>.

LIANOS, Michalis. (2003), "Le contrôle social après Foucault”. Surveillance \& Society, 1 (3). Disponível em <http:/www.surveillance-and-society.org/articles1(3)/ApresFoucault.pdf >.

LYON, David. (2001), Surveillance society: monitoring everyday life. Buckingham, Open University Press.

MISSE, Michel. (2006), Crime e violência no Brasil contemporâneo: estudos de sociologia do crime e da violência urbana. Rio de Janeiro, Lúmen Júris.

SEKULA, Allan. (1986), "The body and the archive". October, 39, The MIT Press.

SMITH, Gavin J. D. (2004), "Behind the screens: examining constructions of deviance and informal practices among CCTV Control Room Operators in the UK”. Surveillance \& Society, 2 (2/3). Disponível em <http://www.surveillance-and-society.org/articles2(2)/screens.pdf>.

STONE, Christopher. (2003), "A importância do controle externo da polícia nas sociedades democráticas: uma perspectiva internacional”, in J. Lemgruber, L. Musumeci e I. Cano (orgs.), Quem vigia os vigias?Um estudo sobre controle externo da polícia no Brasil, Rio de Janeiro/São Paulo, Record.
WHITAKER, Reg. (1999), The end of privacy: how total surveillance is becoming a reality. Nova York, The New Press. 


\section{CÂMERAS LEGISLATIVAS: VIDEOVIGILÂNCIA E LEIS NO RIO DE JANEIRO}

\section{Bruno Cardoso}

Palavras-chave: Videovigilância; Insegurança; Tecnologia; Relações sociotécnicas.

A partir da discussão legislativa em torno da videovigilância e do trabalho de campo realizado com os operadores de câmeras da Secretaria de Segurança Pública do Rio de Janeiro, o presente artigo debate importantes aspectos constituintes da videovigilância. Em especial, são analisadas a fragmentação dos sentidos e a sobredeterminação técnica, e sua implicação tanto nas expectativas em torno da videovigilância como na realização prática do trabalho de monitoramento por câmeras.

\section{VIDEO CAMERAS AND THE LEGISLATIVE ASSEMBLY: VIDEO SURVEILLANCE AND THE LAW IN RIO DE JANEIRO}

\section{Bruno Cardoso}

Keywords: Video surveillance; Insecurity; Technology; Legislative; Sociotechnical relations.

Based on the legislative debates around the issue of video surveillance and on the fieldwork carried out with the camera operators of the Public Security Department of Rio de Janeiro, the present article discusses important constitutive aspects of the video surveillance. Especially analyzed are the meaning fragmentation and the technical overdetermination, and their implications as well in the expectations around the video surveillance as in the practical accomplishment of the task of video monitoring.
CAMÉRAS ET DÉBAT LEGISLATIF: LA VIDÉO SURVEILLANCE ET LA LOI À RIO DE JANEIRO

\section{Bruno Cardoso}

Mots-clés: Vidéo surveillance ; Insécurité ; Technologie ; Législation ; Rapports sociotechniques.

À partir du débat législatif autour de la vidéo surveillance et du travail de terrain avec les opérateurs de caméras du Secrétariat de Sécurité Publique de Rio de Janeiro, cet article aborde quelques aspects importants qui composent la vidéo surveillance. Il analyse, en particulier, la fragmentation des sens et la surdétermination technique ainsi que leur implication dans les attentes autour de la vidéo surveillance et dans le travail de mise en place de la surveillance par caméras. 